Published in final edited form as:

Semin Thromb Hemost. 2017 October ; 43(7): 691-698. doi:10.1055/s-0037-1602664.

\title{
Heparin-Induced Thrombocytopenia in Cardiac Surgery Patients
}

\author{
Allyson M. Pishko, MD $^{1}$ and Adam Cuker, MD, MS $^{1,2}$ \\ ${ }^{1}$ Department of Medicine, Perelman School of Medicine, University of Pennsylvania, Philadelphia, \\ Pennsylvania \\ 2Department of Pathology and Laboratory Medicine, Perelman School of Medicine, University of \\ Pennsylvania, Philadelphia, Pennsylvania
}

\begin{abstract}
Heparin-induced thrombocytopenia (HIT) is a prothrombotic disorder mediated by plateletactivating antibodies that target complexes of platelet factor 4 (PF4) and heparin. Because nearly all patients undergoing cardiopulmonary bypass (CPB) are exposed to heparin and experience a postoperative platelet count fall, it is not surprising that HIT is commonly suspected in this population. However, the incidence of HIT in cardiac surgery patients who receive intraoperative and postoperative unfractionated heparin is much lower than the incidence of suspected HIT, being approximately 1 to $2 \%$. Clinical diagnosis may therefore be particularly challenging because of the need to distinguish the common platelet count fall associated with $\mathrm{CPB}$ and surgery from the much less common platelet count fall associated with HIT. A biphasic platelet count pattern is characteristic of HIT in this setting. Laboratory diagnosis is also difficult because of the high frequency of anti-PF4/heparin antibody seropositivity after cardiac surgery in patients without HIT. A unique aspect of management in the cardiac surgery setting is selecting an anticoagulant for intraoperative use in patients with a history of HIT who require cardiac surgery. In this article, we review the epidemiology, clinical diagnosis, and laboratory diagnosis of HIT in cardiac surgery patients and present a conceptual framework for selecting intraoperative anticoagulation in patients with a history of HIT.
\end{abstract}

\section{Keywords}

cardiac surgery; cardiopulmonary bypass; heparin; heparin-induced thrombocytopenia; thrombocytopenia

\footnotetext{
Heparin-induced thrombocytopenia (HIT) is a feared complication of heparin exposure caused by platelet-activating IgG antibodies that recognize multimolecular complexes of platelet factor 4 (PF4) and heparin. ${ }^{1,2}$ Major clinical manifestations include a fall in platelet

Address for correspondence Adam Cuker, MD, MS, Hospital of the University of Pennsylvania, 3400 Spruce Street, Philadelphia, PA 19104 (adam.cuker@uphs.upenn.edu).

Issue Theme Thrombosis and Hemostasis in Surgery; Guest Editors: Anne-Mette Hvas, MD, PhD, Julie Brogaard Larsen, MD, and Leonardo Pasalic, PhD, MBBS, FRCPA, FRACP.

Disclosures

A.C. has served as a consultant for Biogen-Idec, Diagnostica Stago, and Genzyme and has received research support from BiogenIdec, Spark Therapeutics, and T2 Biosystems. A.P. has no conflicts to declare.
} 
count and perhaps counterintuitively a profound hypercoagulable state, which may lead to limb- or life-threatening thrombosis. Left untreated, the initial rate of thromboembolism, amputation, and death in patients with acute HIT is $6.1 \%$ per day. ${ }^{3}$ Diagnosis rests on a combination of clinical assessment and laboratory demonstration of anti-PF4/heparin antibodies that activate platelets in a heparin-dependent manner. ${ }^{4}$ Treatment involves discontinuation of heparin and initiation of a nonheparin anticoagulant. ${ }^{5}$

Nearly all patients undergoing cardiac surgery receive intraoperative heparin and experience a fall in platelet count after surgery. It is thus not surprising that the specter of HIT is commonly raised in this population. Several factors conspire to make diagnosis especially challenging after cardiac surgery, including the need to distinguish the common platelet count fall associated with surgery and cardiopulmonary bypass (CPB) from the less common fall associated with HIT, the frequency of digital ischemia, and the high rate of anti-PF4/ heparin antibody seropositivity. Management in the cardiac surgery setting also presents unique challenges, particularly decisions about intraoperative anticoagulation in patients with a history of HIT. Herein, we review the epidemiology of HIT after cardiac surgery, discuss special considerations regarding clinical and laboratory diagnosis in this setting, and propose a conceptual framework for selecting intraoperative anticoagulation in patients with a history of HIT who require cardiac surgery.

\section{Epidemiology}

HIT occurs in less than 0.1 to $5 \%$ of patients exposed to heparin, depending on the patient population, type of heparin, and duration of heparin exposure. ${ }^{6}$ In general, HIT is more prevalent among surgical than medical patients and more common with unfractionated heparin (UFH) than with low-molecular-weight heparin (LMWH). ${ }^{7,8}$ Among certain surgical populations such as orthopedic surgery and trauma patients, the prevalence of HIT has probably declined as UFH has been largely replaced with LMWH in countries where LMWH is available. ${ }^{9,10}$ HIT remains relatively common after cardiovascular surgery, however, possibly because of the continued use of intraoperative UFH.

Prospective and retrospective studies of cardiac surgery patients receiving intraoperative UFH and postoperative UFH thromboprophylaxis suggest an overall incidence of HIT of 1 to $5 \%{ }^{8,11-13}$ Studies differed in how HIT was ascertained and diagnosed, potentially accounting for the variability in incidence estimates.

Two groups have examined whether replacement of postoperative UFH with LMWH after cardiac surgery reduces the risk of HIT. Pouplard and colleagues conducted a cohort study of 437 and 1,874 cardiac surgery patients who received postoperative UFH and LMWH, respectively. ${ }^{11}$ The incidence of HIT was significantly greater in the UFH cohort (2.5 vs. $0.4 \%, p<0.0001$ ), but baseline differences in the two treatment groups in this nonrandomized study preclude inferences about causation. ${ }^{11}$ Selleng and coworkers compared UFH and LMWH after cardiac surgery in a prospective cohort study. ${ }^{14}$ HIT occurred in $0.9 \%$ of patients in the UFH group and $0 \%$ in the LMWH group $(p=0.23)$. Interpretation of these results is potentially confounded by indication bias. UFH was administered (in therapeutic doses) only in patients who had an indication for therapeutic 
intensity anticoagulation, whereas prophylactic intensity LMWH was given to all other patients. ${ }^{14}$

Most epidemiologic data on HIT in cardiac surgery have been collected in patients undergoing coronary artery bypass grafting $(\mathrm{CABG})$ or valve surgery on CPB. There is less information about the risk of HIT with off-pump or other types of cardiac surgery. Several small studies demonstrate a high rate of heparin-dependent platelet-activating antibody formation (7.8-10.6\%) after ventricular assist device implantation, ${ }^{15-17}$ though the incidence of clinical HIT in this setting is not well established. The possibility of HIT is frequently raised in patients on extracorporeal membrane oxygenation (ECMO), but data on the incidence of HIT in this group are lacking. ${ }^{18}$ In a single center, 22 of 165 (13.3\%) patients were classified as having HIT after cardiac transplantation. This figure is probably an overestimate of the true incidence of HIT because not all cases were confirmed with a functional assay. ${ }^{19}$

Taken together, published data suggest that the incidence of HIT in adults undergoing CABG or valve surgery on CPB who receive intraoperative UFH and postoperative UFH thromboprophylaxis is on the order of 1 to $2 \%$. More data are needed to determine whether replacement of postoperative UFH with LMWH reduces the risk.

\section{Diagnosis}

Although the overall incidence of HIT in cardiac surgery patients is on the order of 1 to $2 \%$, $8,11,12$ suspected HIT in this population is far more common. In contemporary series of consecutive patients referred for HIT laboratory testing because of suspected HIT, 36 to 51\% were drawn from the cardiac surgery population. ${ }^{20-24}$

Heparin use is nearly universal in cardiac surgery patients and nearly all patients experience a platelet count drop following CPB. ${ }^{25}$ Thus, it is of little surprise that HIT is frequently considered in the context of cardiac surgery. Physicians must therefore rely on a combination of clinical assessment and laboratory testing to differentiate the 1 to $2 \%$ of patients with true HIT from the far more numerous patients with thrombocytopenia due to other etiologies.

\section{Clinical Diagnosis}

Estimation of the clinical or pretest probability of HIT relies on careful assessment of various clinical features including thrombocytopenia, the timing of the platelet count fall relative to heparin exposure, the presence of thrombosis or other sequelae of HIT, and the likelihood of other causes of thrombocytopenia. As detailed below, each of these features warrants special consideration in cardiac surgery patients.

Timing-In typical-onset HIT, the platelet count fall characteristically begins 5 to 10 days after the immunizing heparin exposure. In cardiac surgery patients, the platelet count fall due to HIT must be differentiated from the fall due to surgery and CPB (after CPB, the platelet count falls by an average of $40 \%$, nadirs $48-72$ hours after surgery, and then begins to recover). ${ }^{11} \mathrm{~A}$ second fall in the platelet count between postoperative days 5 and 10 is highly 
suspicious for HIT. This biphasic pattern is illustrated in the patient example in Fig. 1. In contrast, a platelet count that falls immediately after CBP and remains low without recovery is rarely attributable to HIT and is much more likely to be due to other causes such as infection. ${ }^{26}$ In a prospective study of 581 cardiac surgery patients, all 3 patients with a biphasic platelet count profile (Fig. 1) and none of 25 patients with early-onset and persistent thrombocytopenia were found to have HIT. ${ }^{14}$

In patients with preexisting anti-PF4/heparin antibodies, reexposure to heparin may result in an immediate fall in platelet count or so-called rapid-onset HIT. Such patients have invariably had exposure to heparin within the recent past, usually within the last 30 days. ${ }^{27}$ It is not uncommon for cardiac surgery patients to have a history of recent heparin exposure (e.g., during preoperative cardiac catheterization). The possibility of rapid-onset HIT must therefore be considered in such patients. However, clinical experience suggests that the UFH administered during cardiac surgery is more likely to be immunizing than preoperative heparin exposure. This explains why early-onset and persistent thrombocytopenia after cardiac surgery is seldom associated with HIT, even among patients with a history of recent heparin exposure. ${ }^{14}$

Thrombocytopenia-Percentage fall in platelet count is measured from the peak platelet count after heparin exposure to the nadir platelet count. The platelet count characteristically declines by $\geq 50 \%$ in HIT, although approximately $10 \%$ of patients experience a more modest fall of 30 to $50 \% .^{28}$

The nadir platelet count need not fall below the conventional laboratory threshold for thrombocytopenia of $150 \times 10^{9} / \mathrm{L}$. This point is particularly important to bear in mind in the evaluation of surgical (including cardiac surgery) patients for HIT. Following cardiac surgery, the platelet count typically surpasses the preoperative baseline on postoperative days 5 to 7 , peaks at approximately day 14, and remains elevated above baseline for several weeks before returning to preoperative levels. ${ }^{11}$ A patient who develops HIT during the period of postoperative thrombocytosis may experience a significant decline ( $250 \%)$ in platelet count that does not fall below $150 \times 10^{9} / \mathrm{L}^{29}$

Thrombosis and Other Manifestations-Thromboembolism occurs in 30 to 50\% of patients with HIT and may be venous or arterial. ${ }^{30-32}$ Although lower extremity deep vein thrombosis and pulmonary embolism are the most common thrombotic manifestations of HIT, there is a predominance of arterial thromboembolism, most commonly involving the extremities, in cardiac surgery patients. ${ }^{33}$

Digital ischemia is a frequent finding among cardiac surgery patients and may be taken as a sign of HIT. Although HIT may cause small vessel thromboembolism and digital ischemia, other etiologies such as hypotension, vasopressors, and underlying peripheral arterial disease are probably more common in this setting. ${ }^{6}$

Other Causes of Thrombocytopenia-A deliberate assessment of the likelihood of other causes of thrombocytopenia should be undertaken in all patients with suspected HIT. As noted previously, after CPB the platelet count falls by a mean of $40 \%$ over the ensuing 48 
to 72 hours. A lesser fall is expected after off-pump surgery. ${ }^{25}$ In one study, intra-aortic balloon pump use resulted in a mean fall in the platelet count of $63 \%$ over 4 days. The platelet count recovered rapidly once the balloon pump was removed. ${ }^{34}$ ECMO is associated with thrombocytopenia, though data on the degree of platelet count fall are lacking. ${ }^{18}$ Thrombocytopenia due to drugs other than heparin must also be considered. Particular to cardiac patients, thrombocytopenia due to use of the glycoprotein IIb/IIIa antagonists occurs in 0.2 to $2 \%$ of patients and may appear within hours of infusion. ${ }^{35}$ An immune response to protamine sulfate, a reversal agent for UFH used during cardiac surgery, has been recently described. ${ }^{36-38}$ Although 25 to $30 \%$ of patients have detectable antiprotamine antibodies 4 to 6 weeks after surgery, the clinical relevance of these antibodies including their contribution to thrombocytopenia is questionable. ${ }^{39}$

Scoring Systems-Scoring systems have been developed to assist clinicians in incorporating the aforementioned laboratory and clinical characteristics into an estimate of the probability of HIT. The most extensively studied scoring system is the 4Ts score (Table 1). ${ }^{20,40}$ Patients are evaluated across four domains (Thrombocytopenia, Timing,

Thrombosis, and o Ther causes) and are assigned a score of 0,1 , or 2 points for each domain, yielding a maximum summative score of 8. A 4Ts score of 0 to 3 points, 4 to 5 points, and 6 to 8 points is said to correspond to a low, intermediate, and high probability of HIT, respectively. In a systematic review and meta-analysis of 13 studies, the negative predictive value of a low probability 4Ts score was $99.8 \%$ (95\% confidence interval [CI]: $97.0-$ $100.0 \%)$. The positive predictive value of an intermediate and high probability 4Ts score was $14 \%(9-22 \%)$ and 64\% (40-82\%), respectively. Although all 13 studies included in the meta-analysis enrolled cardiac surgery patients, the studies did not provide patient-level data necessary for defining operating characteristics of the 4Ts score specific to the cardiac surgery population. A sensitivity analysis showed that the negative predictive value of a low probability 4Ts score remained high irrespective of whether a study included a large $(>36 \%)$ or a small $(<18 \%)$ proportion of cardiac surgery patients, suggesting that a low probably $4 \mathrm{Ts}$ score may be a robust means of ruling out HIT in cardiac surgery patients. ${ }^{41}$ The 4 Ts score is limited by modest interobserver agreement. ${ }^{42}$ In one real-world study, raw interobserver agreement ranged between 48 and $65 \% .{ }^{43}$ Although the interobserver agreement of the 4Ts score specific to cardiac surgery patients has not been reported, one could speculate that there is potential for subjective interpretation and inter-rater variability in this setting. Despite these concerns, we believe that the 4Ts score is a useful tool for estimating the clinical probability of HIT after cardiac surgery, provided that special considerations unique to this setting are borne in mind. The 4Ts score and special considerations for cardiac surgery patients are shown in Table 1 .

Other clinical scoring systems for HIT remain to be validated. ${ }^{23,44,45}$ One such scoring system, developed by Lillo-Le Louët and colleagues, was designed specifically for assessment of HIT after CBP. ${ }^{44}$ The model was derived from 84 patients with suspected HIT following CPB. Independent risk factors for HIT in the derivation cohort included a biphasic platelet count profile, an interval of $\geq 5$ days from CPB to suspected HIT, and a CPB duration of $\geq 118$ minutes. These variables were used to build a model, which correctly 
classified 34 of 35 HIT-positive patients and 28 of 49 HIT-negative patients in the derivation cohort. The Lillo-Le Louët model has not been validated in an independent cohort.

\section{Laboratory Diagnosis}

In view of the challenges of clinical diagnosis, physicians must rely heavily on HIT laboratory testing to assist with diagnosis. Laboratory assays for HIT fall into two categories, immunological and functional. Immunoassays detect circulating anti-PF4/heparin antibodies, irrespective of whether they are able to activate platelets and cause HIT.

Functional assays such as the serotonin release assay and heparin-induced platelet activation assay detect only those antibodies that have the capacity to activate platelets in a heparindependent manner. Immunoassays are more widely available and highly sensitive, but are associated with limited specificity. ${ }^{46,47}$ Functional assays are highly specific for HIT, but are complex to perform, require specialized reagents and methods, and are thus offered by only a small number of specialized reference laboratories, often with turnaround times of several days. As such, functional assays may be useful for diagnostic confirmation, but results are generally not available to inform initial management decisions.

The seroprevalence of anti-PF4/heparin antibodies among cardiac surgery patients is striking. Preoperative antibodies are present in 5 to $22 \% .{ }^{48}$ Within 1 week after CPB, 22 to $52 \%$ of patients have circulating anti-PF4/heparin antibodies. ${ }^{49-52}$ Given that the incidence of HIT in this setting is only 1 to $2 \%$ (see section on Epidemiology), the implication of these data is that false-positive immunoassay results will outnumber true positives by at least 10:1. Using an IgG-specific detection system and/or increasing the diagnostic threshold may improve specificity, ${ }^{53,54}$ but the potential for overdiagnosis remains enormous. ${ }^{55}$ The risks associated with a false diagnosis of HIT are significant and include exposure to costly parenteral nonheparin anticoagulants and their attendant risk of major bleeding $(\sim 1 \%$ per day). ${ }^{4}$ Therefore, immunoassay testing must be coupled with careful clinical assessment and a positive immunoassay test should be confirmed with a functional assay.

Several studies have investigated whether anti-PF4/heparin antibodies in cardiac surgery patients without HIT are associated with adverse outcomes. In a systematic review of five studies, preoperative antibodies were not associated with postoperative thromboembolism or mortality. ${ }^{48}$ Data regarding the clinical relevance of anti-PF4/heparin antibodies detected after surgery are mixed. Several studies suggest a higher incidence of myocardial infarction, stroke, venous thromboembolism, and death in antibody-positive patients, ${ }^{51,56,57}$ while others do not. ${ }^{49,50,52,58}$ In general, an immunoassay should only be ordered in a cardiac surgery patient with suspected HIT (i.e., should not be used for "screening" unselected patients) because the clinical relevance of anti-PF4/heparin antibodies in patients without HIT is not established and because the high rate of seropositivity could lead to misdiagnosis and inappropriate management.

\section{Management}

The clinical and immunological response to suspension of heparin in a patient with acute HIT follows a predictable pattern. Platelet count recovery occurs within 10 days of heparin cessation in $90 \%$ of patients, though it may take weeks in a minority of individuals. 
Functional assays and immunoassays become negative at a median of 50 and 85 days, respectively. ${ }^{27}$ On the basis of this stereotyped sequence of events, HIT may be conceptually divided into phases (Table 2). ${ }^{59}$ Acute HIT persists until platelet count recovery and is a period of markedly increased thrombotic risk. The period from platelet count recovery until the functional assay becomes negative is termed subacute HIT A. Subacute HIT B is the phase after the functional assay becomes negative, but before the immunoassay becomes negative. Finally, once anti-PF4/heparin antibodies are no longer detectable by immunoassay, the patient is said to have remote HIT. This conceptual framework is useful because it reflects the multiple phases in which HIT is encountered and the different management questions with which clinicians are confronted in clinical practice, particularly in the cardiac surgery setting. ${ }^{59}$

The management of acute HIT after cardiac surgery is similar to the management of acute HIT in other settings and will not be reviewed here. The reader is referred to recent clinical practice guidelines and review articles for more information. ${ }^{59-62}$ Herein, we focus on an aspect of management unique to the cardiac surgery setting: selection of intra-operative anticoagulation in patients with a history of HIT.

\section{Intraoperative Anticoagulation for Cardiac Surgery}

Selection of the intraoperative anticoagulant for cardiac surgery depends primarily on the phase of HIT (Table 2). UFH is the preferred choice in patients without a history of HIT because of its measurability, reversibility, low cost, and familiarity to surgeons and perfusionists. However, it is unsafe to expose patients with acute HIT or subacute HIT A to heparin because of the risk of HIT recurrence or exacerbation. In these patients, cardiac surgery should be postponed if possible until the functional assay becomes negative (i.e., subacute HIT B) and ideally until anti-PF4/heparin antibodies are no longer present (i.e., remote HIT). If surgery cannot be delayed, a nonheparin anticoagulant such as bivalirudin should be used. Bivalirudin protocols for both on-pump and off-pump surgery have been published. ${ }^{63-66}$ Alternatively, the patient may be treated with preoperative plasma exchange to remove platelet-activating antibodies and enable intraoperative UFH. This approach appears to be safe, but data are limited. ${ }^{67,68}$

In patients with subacute HIT B or remote HIT, UFH is the intraoperative anticoagulant of choice (Table 2). The safety of administering intraoperative UFH in patients with remote HIT was first established in a series of 10 patients undergoing cardiac surgery. None developed HIT or recrudescence of HIT antibodies. ${ }^{69}$ There is mounting evidence that intraoperative UFH is also safe in patients with subacute HIT B. In three patients with subacute HIT B who required urgent cardiac transplantation, treatment with intraoperative UFH did not result in clinical recurrence. ${ }^{70}$ Similar findings were reported in a recently published series of 10 patients. ${ }^{71}$

In patients with subacute HIT B, it is advisable to delay surgery until anti-PF4/heparin antibodies are no longer detectable. In patients with subacute HIT B in whom surgery cannot be delayed and in patients with remote HIT, intraoperative UFH is recommended over a nonheparin anticoagulant (Table 2). When a cardiac surgery patient with a history of HIT is 
reexposed to heparin, exposure should be strictly limited to the intraoperative setting. If preor postoperative anticoagulation is indicated, a nonheparin anticoagulant should be used.

\section{Conclusion}

Even as the incidence of HIT falls in other clinical settings due to replacement of UFH by LMWH,${ }^{72}$ HIT remains a threat in cardiac surgery patients, perhaps in part because of the continued preference for intraoperative UFH. HIT affects 1 to $2 \%$ of patients who undergo CPB followed by postoperative UFH thromboprophylaxis. More data are needed to determine whether LMWH thromboprophylaxis is associated with a reduction in the incidence of HIT.

The number of cardiac surgery patients in whom HIT is suspected far exceeds those in whom the disease is ultimately confirmed. Several factors contribute to the high rate of suspicion and the potential for overdiagnosis of HIT in this population including the ubiquity of heparin exposure and thrombocytopenia, the frequent presence of digital ischemia, and the striking proportion of anti-PF4/heparin seropositivity among patients without HIT. Careful clinical assessment with special consideration of the features characteristic of HIT after cardiac surgery (Table 1) is therefore paramount to determine which patients are appropriate for HIT laboratory testing. Of equal importance, positive immunoassay results should be confirmed with a more specific functional assay to minimize the short- and long-term harms of misdiagnosis. ${ }^{73}$

In patients with a history of HIT who require cardiac surgery, laboratory testing may be used to define the phase of the disease and guide decisions about intraoperative anticoagulation (Table 2). UFH is recommended in those with remote HIT and subacute HIT B. In patients with acute HIT or subacute HIT A, a nonheparin anticoagulant (e.g., bivalirudin) or preoperative plasma exchange should be used if surgery cannot be delayed.

For more than a decade, experts have predicted the demise of HIT. While its incidence has, indeed, fallen in other clinical settings due to declining use of UFH, it remains a real problem in the cardiac surgery setting, where UFH, for the foreseeable future, will continue to be the intraoperative anticoagulant of choice. We would therefore do well to continue to investigate HIT in the cardiac surgery setting with a focus on developing strategies for prevention and improved clinical and laboratory diagnostic tools.

\section{Acknowledgments}

A.P. is supported by T32 HL007971-15 from the National Institutes of Health.

\section{References}

1. Amiral J, Bridey F, Dreyfus M, et al. Platelet factor 4 complexed to heparin is the target for antibodies generated in heparin-induced thrombocytopenia. Thromb Haemost. 1992; 68(01):95-96. [PubMed: 1514184]

2. Rauova L, Poncz M, McKenzie SE, et al. Ultralarge complexes of PF4 and heparin are central to the pathogenesis of heparin-induced thrombocytopenia. Blood. 2005; 105(01):131-138. [PubMed: 15304392] 
3. Greinacher A, Eichler P, Lubenow N, Kwasny H, Luz M. Heparin-induced thrombocytopenia with thromboembolic complications: meta-analysis of 2 prospective trials to assess the value of parenteral treatment with lepirudin and its therapeutic aPTT range. Blood. 2000; 96(03):846-851. [PubMed: 10910895]

4. Cuker A. Clinical and laboratory diagnosis of heparin-induced thrombocytopenia: an integrated approach. Semin Thromb Hemost. 2014; 40(01):106-114. [PubMed: 24363239]

5. Cuker A. Current and emerging therapeutics for heparin-induced thrombocytopenia. Semin Thromb Hemost. 2012; 38(01):31-37. [PubMed: 22314601]

6. Cuker A, Cines DB. How I treat heparin-induced thrombocytopenia. Blood. 2012; 119(10):22092218. [PubMed: 22246036]

7. Martel N, Lee J, Wells PS. Risk for heparin-induced thrombocytopenia with unfractionated and lowmolecular-weight heparin thromboprophylaxis: a meta-analysis. Blood. 2005; 1062710(08):2715.

8. Warkentin TE, Sheppard JA, Horsewood P, Simpson PJ, Moore JC, Kelton JG. Impact of the patient population on the risk for heparin-induced thrombocytopenia. Blood. 2000; 96(05):1703-1708. [PubMed: 10961867]

9. Warkentin TE, Levine MN, Hirsh J, et al. Heparin-induced thrombocytopenia in patients treated with low-molecular-weight heparin or unfractionated heparin. N Engl J Med. 1995; 332(20):13301335. [PubMed: 7715641]

10. Lubenow N, Hinz P, Thomaschewski S, et al. The severity of trauma determines the immune response to PF4/heparin and the frequency of heparin-induced thrombocytopenia. Blood. 2010; 115(09):1797-1803. [PubMed: 19965682]

11. Pouplard C, May MA, Iochmann S, et al. Antibodies to platelet factor 4-heparin after cardiopulmonary bypass in patients anticoagulated with unfractionated heparin or a lowmolecular-weight heparin: clinical implications for heparin-induced thrombocytopenia. Circulation. 1999; 99(19):2530-2536. [PubMed: 10330384]

12. Walls JT, Curtis JJ, Silver D, Boley TM, Schmaltz RA, Nawarawong W. Heparin-induced thrombocytopenia in open heart surgical patients: sequelae of late recognition. Ann Thorac Surg. 1992; 53(05):787-791. [PubMed: 1570971]

13. Singer RL, Mannion JD, Bauer TL, Armenti FR, Edie RN. Complications from heparin-induced thrombocytopenia in patients undergoing cardiopulmonary bypass. Chest. 1993; 104(05):14361440. [PubMed: 8222802]

14. Selleng S, Malowsky B, Strobel U, et al. Early-onset and persisting thrombocytopenia in postcardiac surgery patients is rarely due to heparin-induced thrombocytopenia, even when antibody tests are positive. J Thromb Haemost. 2010; 8(01):30-36. [PubMed: 19793190]

15. Schenk S, El-Banayosy A, Prohaska W, et al. Heparin-induced thrombocytopenia in patients receiving mechanical circulatory support. J Thorac Cardiovasc Surg. 2006; 131(06):1373-81.e4. [PubMed: 16733172]

16. Schenk S, El-Banayosy A, Morshuis M, et al. IgG classification of anti-PF4/heparin antibodies to identify patients with heparin-induced thrombocytopenia during mechanical circulatory support. J Thromb Haemost. 2007; 5(02):235-241. [PubMed: 17083649]

17. Koster A, Huebler S, Potapov E, et al. Impact of heparin-induced thrombocytopenia on outcome in patients with ventricular assist device support: single-institution experience in 358 consecutive patients. Ann Thorac Surg. 2007; 83(01):72-76. [PubMed: 17184633]

18. Murphy DA, Hockings LE, Andrews RK, et al. Extracorporeal membrane oxygenation-hemostatic complications. Transfus Med Rev. 2015; 29(02):90-101. [PubMed: 25595476]

19. Hassan S, Qureshi W, Badami A, et al. Heparin-induced thrombocytopenia: is it a graft-threatening complication? Transpl Int. 2013; 26(04):385-391. [PubMed: 23293891]

20. Lo GK, Juhl D, Warkentin TE, Sigouin CS, Eichler P, Greinacher A. Evaluation of pretest clinical score (4 T's) for the diagnosis of heparin-induced thrombocytopenia in two clinical settings. J Thromb Haemost. 2006; 4(04):759-765. [PubMed: 16634744]

21. Bryant A, Low J, Austin S, Joseph JE. Timely diagnosis and management of heparin-induced thrombocytopenia in a frequent request, low incidence single centre using clinical 4T's score and particle gel immunoassay. Br J Haematol. 2008; 143(05):721-726. [PubMed: 19036016] 
22. Denys B, Stove V, Philippé J, Devreese K. A clinical-laboratory approach contributing to a rapid and reliable diagnosis of heparin-induced thrombocytopenia. Thromb Res. 2008; 123(01):137145. [PubMed: 18582919]

23. Cuker A, Arepally G, Crowther MA, et al. The HIT Expert Probability (HEP) Score: a novel pretest probability model for heparin-induced thrombocytopenia based on broad expert opinion. J Thromb Haemost. 2010; 8(12):2642-2650. [PubMed: 20854372]

24. Tawfik NM, Hegazy MA, Hassan EA, Ramadan YK, Nasr AS. Egyptian experience of reliability of 4T's score in diagnosis of heparin induced thrombocytopenia syndrome. Blood Coagul Fibrinolysis. 2011; 22(08):701-705. [PubMed: 22008905]

25. Nader ND, Khadra WZ, Reich NT, Bacon DR, Salerno TA, Panos AL. Blood product use in cardiac revascularization: comparison of on-and off-pump techniques. AnnThorac Surg. 1999; 68(05):1640-1643.

26. Gruel Y, Pouplard C. Post-operative platelet count profile: the most reliable tool for identifying patients with true heparin-induced thrombocypenia after cardiac surgery. $\mathrm{J}$ Thromb Haemost. 2010; 8(01):27-29. [PubMed: 19817999]

27. Warkentin TE, Kelton JG. Temporal aspects of heparin-induced thrombocytopenia. N Engl J Med. 2001; 344(17):1286-1292. [PubMed: 11320387]

28. Warkentin TE. Clinical presentation of heparin-induced thrombocytopenia. Semin Hematol. 1998; 35(04, Suppl 5):9-16. discussion 35-36.

29. Warkentin TE, Roberts RS, Hirsh J, Kelton JG. An improved definition of immune heparininduced thrombocytopenia in postoperative orthopedic patients. Arch Intern Med. 2003; 163(20): 2518-2524. [PubMed: 14609790]

30. Warkentin TE, Kelton JG. A 14-year study of heparin-induced thrombocytopenia. Am J Med. 1996; 101(05):502-507. [PubMed: 8948273]

31. Nand S, Wong W, Yuen B, Yetter A, Schmulbach E, Gross Fisher S. Heparin-induced thrombocytopenia with thrombosis: incidence, analysis of risk factors, and clinical outcomes in 108 consecutive patients treated at a single institution. Am J Hematol. 1997; 56(01):12-16. [PubMed: 9298861]

32. Wallis DE, Lewis BE, Walenga JM. Failure of current strategies in the prevention of thrombosis in patients with heparin-induced thrombocytopenia: a clinician's perspective. Semin Thromb Hemost. 1999; 25(Suppl 1):3-7.

33. Greinacher A, Farner B, Kroll H, Kohlmann T, Warkentin TE, Eichler P. Clinical features of heparin-induced thrombocytopenia including risk factors for thrombosis. A retrospective analysis of 408 patients. Thromb Haemost. 2005; 94(01):132-135. [PubMed: 16113796]

34. Vonderheide RH, Thadhani R, Kuter DJ. Association of thrombocytopenia with the use of intraaortic balloon pumps. Am J Med. 1998; 105(01):27-32. [PubMed: 9688018]

35. Matthai WH Jr. Thrombocytopenia in cardiovascular patients: diagnosis and management. Chest. 2005; 127(2, Suppl):46S-52S. [PubMed: 15706030]

36. Lee GM, Welsby IJ, Phillips-Bute B, Ortel TL, Arepally GM. High incidence of antibodies to protamine and protamine/heparin complexes in patients undergoing cardiopulmonary bypass. Blood. 2013; 121(15):2828-2835. [PubMed: 23422751]

37. Bakchoul T, Zöllner H, Amiral J, et al. Anti-protamine-heparin antibodies: incidence, clinical relevance, and pathogenesis. Blood. 2013; 121(15):2821-2827. [PubMed: 23325832]

38. Pouplard C, Leroux D, Rollin J, Amiral J, May MA, Gruel Y. Incidence of antibodies to protamine sulfate/heparin complexes in cardiac surgery patients and impact on platelet activation and clinical outcome. Thromb Haemost. 2013; 109(06):1141-1147. [PubMed: 23636177]

39. Cuker A, Cines DB. Protamine-induced thrombocytopenia? Blood. 2013; 121(15):2818-2819. [PubMed: 23580634]

40. Warkentin TE, Heddle NM. Laboratory diagnosis of immune heparin-induced thrombocytopenia. Curr Hematol Rep. 2003; 2(02):148-157. [PubMed: 12901146]

41. Cuker A, Gimotty PA, Crowther MA, Warkentin TE. Predictive value of the 4Ts scoring system for heparin-induced thrombocytopenia: a systematic review and meta-analysis. Blood. 2012; 120(20): 4160-4167. [PubMed: 22990018] 
42. Berry C, Tcherniantchouk O, Ley EJ, et al. Overdiagnosis of heparin-induced thrombocytopenia in surgical ICU patients. J Am Coll Surg. 2011; 213(01):10-17. discussion 17-18. [PubMed: 21531584]

43. Nagler M, Fabbro T, Wuillemin WA. Prospective evaluation of the interobserver reliability of the 4Ts score in patients with suspected heparin-induced thrombocytopenia. J Thromb Haemost. 2012; 10(01):151-152. [PubMed: 22060821]

44. Lillo-Le Louët A, Boutouyrie P, Alhenc-Gelas M, et al. Diagnostic score for heparin-induced thrombocytopenia after cardiopulmonary bypass. J Thromb Haemost. 2004; 2(11):1882-1888. [PubMed: 15550015]

45. Messmore HL, Fabbrini N, Bird ML, et al. Simple scoring system for early management of heparin-induced thrombocytopenia. Clin Appl Thromb Hemost. 2011; 17(02):197-201. [PubMed: 21159704]

46. Nagler M, Bachmann LM, ten Cate H, ten Cate-Hoek A. Diagnostic value of immunoassays for heparin-induced thrombocytopenia: a systematic review and meta-analysis. Blood. 2016; 127(05): 546-557. [PubMed: 26518436]

47. Sun L, Gimotty PA, Lakshmanan S, Cuker A. Diagnostic accuracy of rapid immunoassays for heparin-induced thrombocytopenia. A systematic review and meta-analysis. Thromb Haemost. 2016; 115(05):1044-1055. [PubMed: 26763074]

48. Yusuf AM, Warkentin TE, Arsenault KA, Whitlock R, Eikelboom JW. Prognostic importance of preoperative anti-PF4/heparin antibodies in patients undergoing cardiac surgery. A systematic review. Thromb Haemost. 2012; 107(01):8-14. [PubMed: 22072088]

49. Bauer TL, Arepally G, Konkle BA, et al. Prevalence of heparin-associated antibodies without thrombosis in patients undergoing cardiopulmonary bypass surgery. Circulation. 1997; 95(05): 1242-1246. [PubMed: 9054855]

50. Everett BM, Yeh R, Foo SY, et al. Prevalence of heparin/platelet factor 4 antibodies before and after cardiac surgery. Ann Thorac Surg. 2007; 83(02):592-597. [PubMed: 17257993]

51. Mattioli AV, Bonetti L, Zennaro M, Ambrosio G, Mattioli G. Heparin/PF4 antibodies formation after heparin treatment: temporal aspects and long-term follow-up. Am Heart J. 2009; 157(03): 589-595. [PubMed: 19249435]

52. Gluckman TJ, Segal JB, Schulman SP, et al. Effect of anti-platelet factor-4/heparin antibody induction on early saphenous vein graft occlusion after coronary artery bypass surgery. J Thromb Haemost. 2009; 7(09):1457-1464. [PubMed: 19552638]

53. Cuker A, Ortel TL. ASH evidence-based guidelines: is the IgG-specific anti-PF4/heparin ELISA superior to the polyspecific ELISA in the laboratory diagnosis of HIT? Hematology (Am Soc Hematol Educ Program). 2009:250-252. [PubMed: 20008206]

54. Raschke RA, Curry SC, Warkentin TE, Gerkin RD. Improving clinical interpretation of the antiplatelet factor 4/heparin enzyme-linked immunosorbent assay for the diagnosis of heparin-induced thrombocytopenia through the use of receiver operating characteristic analysis, stratum-specific likelihood ratios, and Bayes theorem. Chest. 2013; 144(04):1269-1275. [PubMed: 23703622]

55. Cuker A. Heparin-induced thrombocytopenia (HIT) in 2011: an epidemic of overdiagnosis. Thromb Haemost. 2011; 106(06):993-994. [PubMed: 22012630]

56. Kerendi F, Thourani VH, Puskas JD, et al. Impact of heparin-induced thrombocytopenia on postoperative outcomes after cardiac surgery. Ann Thorac Surg. 2007; 84(05):1548-1553. discussion 1554-1555. [PubMed: 17954061]

57. Mattioli AV, Bonetti L, Carletti U, Ambrosio G, Mattioli G. Thrombotic events in patients with antiplatelet factor 4/heparin antibodies. Heart. 2009; 95(16):1350-1354. [PubMed: 19482851]

58. Welsby IJ, Krakow EF, Heit JA, et al. The association of anti-platelet factor 4/heparin antibodies with early and delayed thromboembolism after cardiac surgery. J Thromb Haemost. 2017; 15(01): 57-65. [PubMed: 27714919]

59. Cuker A. Management of the multiple phases of heparin-induced thrombocytopenia. Thromb Haemost. 2016; 116(05):835-842. [PubMed: 27075525]

60. Linkins LA, Dans AL, Moores LK, et al. Treatment and prevention of heparin-induced thrombocytopenia: Antithrombotic Therapy and Prevention of Thrombosis, 9th ed: American 
College of Chest Physicians Evidence-Based Clinical Practice Guidelines. Chest. 2012; 141:e495S-e530S. [PubMed: 22315270]

61. Watson H, Davidson S, Keeling D, Haemostasis and Thrombosis Task Force of the British Committee for Standards in Haematology. Guidelines on the diagnosis and management of heparin-induced thrombocytopenia: second edition. Br J Haematol. 2012; 159:528-540. [PubMed: 23043677]

62. Greinacher A. CLINICAL PRACTICE. Heparin-induced thrombocytopenia. N Engl J Med. 2015; 373(03):252-261. [PubMed: 26176382]

63. Dyke CM, Smedira NG, Koster A, et al. A comparison of bivalirudin to heparin with protamine reversal in patients undergoing cardiac surgery with cardiopulmonary bypass: the EVOLUTIONON study. J Thorac Cardiovasc Surg. 2006; 131(03):533-539. [PubMed: 16515902]

64. Koster A, Spiess B, Jurmann M, et al. Bivalirudin provides rapid, effective, and reliable anticoagulation during off-pump coronary revascularization: results of the "EVOLUTION OFF" trial. Anesth Analg. 2006; 103(03):540-544. [PubMed: 16931658]

65. Koster A, Dyke CM, Aldea G, et al. Bivalirudin during cardiopulmonary bypass in patients with previous or acute heparin-induced thrombocytopenia and heparin antibodies: results of the CHOOSE-ON trial. Ann Thorac Surg. 2007; 83(02):572-577. [PubMed: 17257990]

66. Dyke CM, Aldea G, Koster A, et al. Off-pump coronary artery bypass with bivalirudin for patients with heparin-induced thrombocytopenia or antiplatelet factor four/heparin antibodies. Ann Thorac Surg. 2007; 84(03):836-839. [PubMed: 17720385]

67. Warkentin TE, Sheppard JA, Chu FV, Kapoor A, Crowther MA, Gangji A. Plasma exchange to remove HIT antibodies: dissociation between enzyme-immunoassay and platelet activation test reactivities. Blood. 2015; 125(01):195-198. [PubMed: 25406354]

68. Welsby IJ, Um J, Milano CA, Ortel TL, Arepally G. Plasmapheresis and heparin reexposure as a management strategy for cardiac surgical patients with heparin-induced thrombocytopenia. Anesth Analg. 2010; 110(01):30-35. [PubMed: 19933539]

69. Pötzsch B, Klövekorn WP, Madlener K. Use of heparin during cardiopulmonary bypass in patients with a history of heparin-induced thrombocytopenia. N Engl J Med. 2000; 343(07):515. [PubMed: 10950681]

70. Selleng S, Haneya A, Hirt S, Selleng K, Schmid C, Greinacher A. Management of anticoagulation in patients with subacute heparin-induced thrombocytopenia scheduled for heart transplantation. Blood. 2008; 112(10):4024-4027. [PubMed: 18791163]

71. Warkentin TE, Anderson JA. How I treat patients with a history of heparin-induced thrombocytopenia. Blood. 2016; 128(03):348-359. [PubMed: 27114458]

72. McGowan KE, Makari J, Diamantouros A, et al. Reducing the hospital burden of heparin-induced thrombocytopenia: impact of an avoid-heparin program. Blood. 2016; 127(16):1954-1959. [PubMed: 26817956]

73. McMahon CM, Tanhehco YC, Cuker A. Inappropriate documentation of heparin allergy in the medical record because of misdiagnosis of heparin-induced thrombocytopenia: frequency and consequences. J Thromb Haemost. 2017; 15(02):370-374. [PubMed: 28012249] 


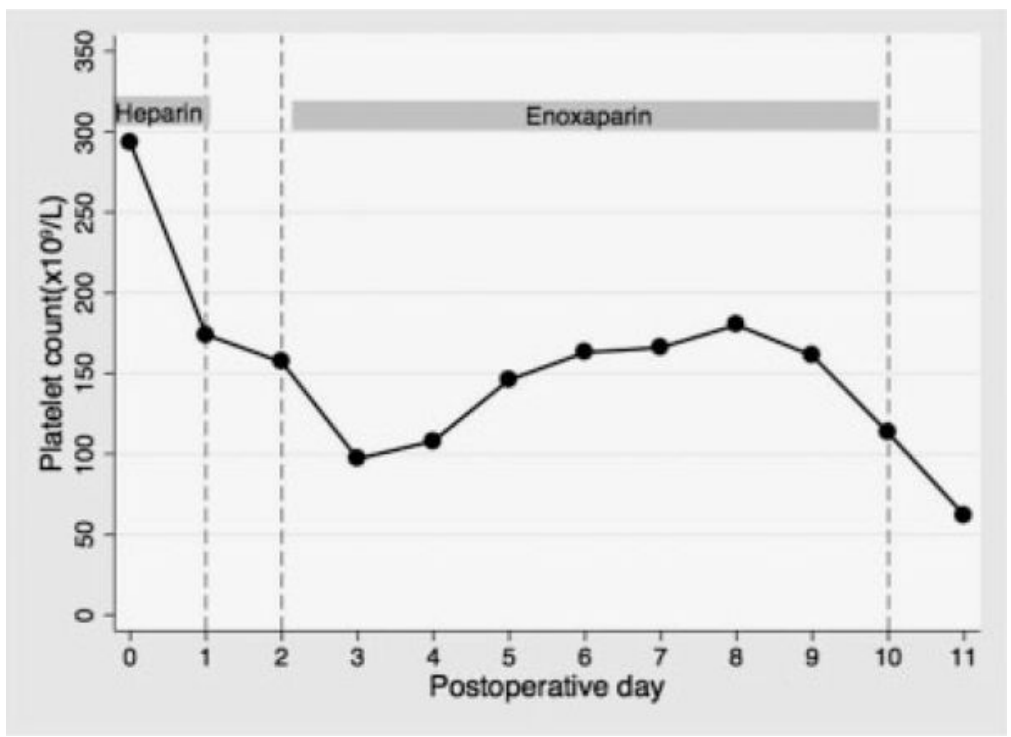

Fig. 1.

Example of biphasic platelet count pattern typical of HIT after cardiopulmonary bypass surgery. A 77-year-old woman underwent elective aortic valve replacement on cardiopulmonary bypass (CPB) on postoperative day 0 . She received unfractionated heparin during surgery and prophylactic intensity enoxaparin beginning on postoperative day 2 . Her preoperative platelet count was $294 \times 10^{9} / \mathrm{L}$. As expected, her platelet count fell after CPB to a nadir of $97 \times 10^{9} / \mathrm{L}$ on postoperative day 3 and then began to recover. Beginning on postoperative day 9 ( 9 days after initial heparin exposure), she experienced a second platelet count fall. Two days later, she became hypoxic and was diagnosed with pulmonary embolism. An anti-PF4/heparin enzyme-linked immunoassay was markedly positive at 2.80 optical density units and a serotonin-release assay was positive. This case illustrates the characteristic biphasic platelet count pattern that is typical of HIT after surgery with CPB. 
Table 1

The 4Ts score and special considerations in application of the 4Ts score to cardiac surgery patients

\begin{tabular}{|c|c|c|c|c|}
\hline 4Ts & 2 points & 1 point & 0 point & Cardiac surgery considerations \\
\hline $\begin{array}{l}\text { Timing of platelet } \\
\text { count fall }\end{array}$ & $\begin{array}{l}\text { Clear onset between } \\
\text { days } 5-14 \text { or platelet } \\
\text { fall } \leq \text { day (prior } \\
\text { heparin exposure } \\
\text { within } 30 \mathrm{~d} \text { ) }\end{array}$ & $\begin{array}{l}\text { Consistent with days } \\
5-14 \text { fall, but not clear } \\
\text { (missing platelet } \\
\text { counts) or onset after } \\
\text { day } 14 \text { or fall } \unlhd d \\
\text { (prior heparin exposure } \\
30-100 \text { d ago) }\end{array}$ & $\begin{array}{l}\text { Platelet } \\
\text { count fall } \\
\leq 4 \mathrm{~d} \\
\text { without } \\
\text { recent } \\
\text { exposure }\end{array}$ & $\begin{array}{l}\text { A biphasic platelet count pattern is typical of HIT } \\
\text { after CPB surgery Early-onset and persistent } \\
\text { thrombocytopenia after CBP is rarely HIT }\end{array}$ \\
\hline Thrombocytopenia & $\begin{array}{l}\text { Platelet count fall } \\
>50 \% \text { and platelet } \\
\text { count nadir } \geq 20 \times \\
109 / \mathrm{L}\end{array}$ & $\begin{array}{l}\text { Platelet count fall } 30- \\
50 \% \text { or platelet nadir } \\
10-19 \times 10^{9} / \mathrm{L}\end{array}$ & $\begin{array}{l}\text { Platelet } \\
\text { count fall } \\
<30 \% \text { or } \\
\text { platelet } \\
\text { nadir }<10 \times \\
10^{9} / \mathrm{L}\end{array}$ & $\begin{array}{l}\text { Percent fall in platelet count is calculated from } \\
\text { peak platelet count following heparin exposure to } \\
\text { nadir platelet count The nadir platelet count need } \\
\text { not fall below } 150 \times 10^{9} / \mathrm{L} \text {, particularly in } \\
\text { surgical patients who have postoperative } \\
\text { thrombocytosis }\end{array}$ \\
\hline $\begin{array}{l}\text { Thrombosis or other } \\
\text { sequelae }\end{array}$ & $\begin{array}{l}\text { New thrombosis } \\
\text { (confirmed); skin } \\
\text { necrosis at heparin } \\
\text { injection sites; } \\
\text { anaphylactoid } \\
\text { reaction after IV } \\
\text { heparin bolus }\end{array}$ & $\begin{array}{l}\text { Progressive or } \\
\text { recurrent thrombosis; } \\
\text { nonnecrotizing } \\
\text { (erythematous) skin } \\
\text { lesions; suspected } \\
\text { thrombosis (not } \\
\text { confirmed) }\end{array}$ & None & $\begin{array}{l}\text { Digital ischemia due to hypotension, } \\
\text { vasopressors, and/or underlying peripheral } \\
\text { arterial disease may mimic HIT-associated small } \\
\text { vessel thromboembolism }\end{array}$ \\
\hline $\begin{array}{l}\text { Other causes of } \\
\text { thrombocytopenia }\end{array}$ & None apparent & Possible & Definite & $\begin{array}{l}\text { Common alternative causes in cardiac patients } \\
\text { include CPB, IABP, ECMO, infection, and other } \\
\text { medications that can cause thrombocytopenia } \\
\text { (e.g., glycoprotein IIb/IIIa antagonists) }\end{array}$ \\
\hline
\end{tabular}

Abbreviations: CPB, cardiopulmonary bypass; ECMO, extracorporeal membrane oxygenation; IABP, intraaortic balloon pump.

Note: A total score of $0-3,4-5$, and 6-8 points is said to correspond to a low, intermediate, and high probability of HIT, respectively. 
Table 2

The multiple phases of HIT and suggestions for intraoperative anticoagulation in patients with a history of HIT

\begin{tabular}{|l|l|l|l|l|}
\hline Phase & Platelet count & Functional assay & Immunoassay & Suggestion \\
\hline Acute & Decreased & + & + & $\begin{array}{l}\text { 1. Delay surgery } \\
\text { 2. If surgery cannot be delayed, use an alternative anticoagulant (e.g., } \\
\text { bivalirudin) or treat with preoperative plasma exchange until } \\
\text { functional assay becomes negative }\end{array}$ \\
\hline Subacute A & Recovered & + & + & $\begin{array}{l}\text { 1. Delay surgery } \\
\text { 2. If surgery cannot be delayed, use heparin }\end{array}$ \\
\hline Subacute B & Recovered & - & + & 1. Use heparin \\
\hline Remote & Recovered & - & - & \\
\hline
\end{tabular}

